\title{
Tailored treatment including radical prostatectomy and radiation therapy + androgen deprivation therapy versus exclusive radical prostatectomy in high-risk prostate cancer patients: results from a prospective study
}

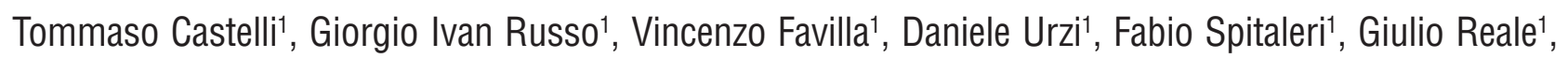
Raimondo Giardina1, Alberto Saita1, Massimo Madonia², Sebastiano Cimino, Giuseppe Morgia

${ }^{1}$ Department of Urology, University of Catania, Catania and ${ }^{2}$ Department of Urology, University of Sassari, Sassari, Italy

\section{ABSTRACT}

Purpose: To evaluate outcomes of patients with high risk prostate cancer (PCa) who underwent radical prostatectomy (RP) in a context of a multidisciplinary approach including adjuvant radiation (RT) + androgen deprivation therapy (ADT).

Matherials and Methods: 244 consecutive patients with high risk localized PCa underwent RP and bilateral extended pelvic lymph node dissection at our institution. Adjuvant RT + 24 months ADT was carried out in subjects with pathological stage $\geq$ T3NO and/or positive surgical margins or in patients with local relapse.

Results: After a median follow-up was 54.17 months (range 5.4-117.16), 13 (5.3\%) subjects had biochemical progression, 21 (8.6\%) had clinical progression, 7 (2.9\%) died due to prostate cancer and 15 (6.1\%) died due to other causes. $136(55.7 \%)$ patients did not receive any adjuvant treatment while 108 (44.3\%) received respectively adjuvant or salvage RT+ADT. Multivariate Cox proportional hazard analysis showed that pre-operative PSA value at diagnosis is a significant predictive factor for BCR (HR: 1.04, $\mathrm{p}<0.05$ ) and that Gleason Score 8-10 (HR: 2.4; $<<0.05)$ and PSMs (HR: 2.01; $\mathrm{p}<0.01$ ) were significant predictors for clinical progression.

Radical prostatectomy group was associated with BPFS, CPFS, CSS and OS at 5-years of 97\%, 90\%, 95\% and 86\% respectively, while adjuvant radiation + androgen deprivation therapy group was associated with a BPFS, CPFS and CSS at 5-years of 91\%, 83\%, 95\% and 88\%, without any statistical difference.

Conclusions: Multimodality tailored treatment based on RP and adjuvant therapy with RT+ADT achieve similar results in terms of OS after 5-years of follow-up.

\section{ARTICLE INFO}

\section{Key words:}

high-risk; prostate cancer; radical prostatectomy; androgen deprivation therapy; radiation therapy; multimodality

Int Braz J Urol. 2014; 40: 322-9

Submitted for publication:

September 24, 2013

Accepted after revision:

March 05, 2014

\section{INTRODUCTION}

Prostate cancer $(\mathrm{PCa})$ is the most commonly diagnosed non-dermatologic malignancy among American men, and it remains the second most fatal cancer. Similar incidence and mortality figures are reported by the European Association of Urology (EAU) (1).

The goal of PCa screening is to detect potential fatal cancers at a time when they may still be curable. The downside of screening is the diagnosis and overtreatment of tumours destined 
to pose no threat to the man during his lifetime. The upside of screening is the detection of high-risk cancers while still clinically localized. In a heavily screened population, this "high-risk" group accounts for $15 \%$ of men with clinically localized disease and likely a higher percentage in less heavily screened population (2).

In the presence of adverse clinical or pathologic features connoting high-risk disease, results of local treatment alone are disappointing and there is increasing recognition of the need for a multimodal approach to treatment $(3,4)$. The optimal sequence and constituents of such a strategy, however, remain controversial. The use of external-beam RT as primary therapy in conjunction with androgen-deprivation therapy (ADT) is supported by the results of several randomized controlled trials (RCTs) (5-8). Alternatively, surgery may be employed as the definitive initial treatment. While radical prostatectomy (RP) has not been traditionally recommended for high-risk disease in the past, its use in this setting is increasing, as evidenced by several large, modern, single-institution series (9-12). Currently, multimodality approaches, including surgery, adjuvant radiotherapy and androgen deprivation therapy are proposed for high risk prostate cancer.

The aim of this study is to evaluate outcomes of patients with high risk prostate cancer who underwent RP in a context of a multidisciplinary approach including surgery alone or adjuvant or salvage radiation therapy + androgen deprivation therapy.

\section{MATERIAL AND METHODS}

\section{Study Population}

From January 2003 to December 2006, 244 consecutive patients with high risk localized PCa (PSA greater than $20 \mathrm{ng} / \mathrm{mL}$, and/or cT3-4 and/or biopsy Gleason Score 8-10) who underwent retropubic radical prostatectomy (RP) and bilateral extended pelvic lymph node dissection (eLND) at a single institution were enrolled in this prospective study.

The protocol was approved by the Internal Institutional Review Board and an informed written consent was obtained from each man before initiation of the study.

Clinical stage was assigned according to the 2002 TNM and prostate biopsy was performed under transperineal ultrasound guidance. Preoperative staging with $\mathrm{CT}$ and bone scan showed no signs of metastases. None of the patients received neoadjuvant ADT. All patients underwent extended lymph node dissection including bilateral dissection of the right and left common iliac vessels, the right and left internal iliac vessels, the right and left external iliac vessels, and the right and left obturator fossa ( $\geq 20$ lymph node).

Follow-up included DRE and serum PSA every 3 months, CT and bone scan annually or when clinically appropriate; TRUS + biopsy of the prostatic bed when clinically required. The baseline information, Charlson Comorbidity Index (CCI), the pathologic Gleason score, surgical margin (SM) status, seminal vesicle invasion (SVI), and the follow-up information were recorded for each subject.

\section{Postoperative therapy}

Postoperative therapy was considered adjuvant therapy if it was begun before PSA or clinical progression. Patients with pathological pelvic lymph node metastases were excluded.

Adjuvant radiotherapy +24 months ADT was carried out in subjects with pathological stage $\geq \mathrm{T} 3 \mathrm{NO}$ and/or positive surgical margins at 4 to 6 weeks after surgery while salvage RT +24 months ADT in patients with local relapse confirmed after biopsy of the prostatic bed. Radiotherapy was performed with intensity-modulated technique using 18-MV photons of an Elekta linear accelerator (Elekta $\mathrm{AB}$, Crawley, UK) equipped with a multileaf collimator. The clinical target volume (CTV) consisted of the postoperative prostate and seminal vesicle bed. To create the planning target volume (PTV), an isotropic, 3-dimensional, 7-mm expansion of the CTV was performed. Treatment was delivered in 37 fractions with a median 76Gy dose to the PTV (range: 70-79 Gy). ADT consisted of triptorelin $11.25 \mathrm{mg}$ administered every 3 months as LHRH analogue.

Biochemical progression after surgery was defined as the first occurrence of two consecutive PSA levels above $0.2 \mathrm{ng} / \mathrm{mL}$ at follow-up. Clinical progression was defined as either local recurrence or distant metastasis. Local recurrence was defined as histologically confirmed evidence of cancer cells 
in targeted biopsies at the prostatic bed. Distant metastasis was defined as a positive finding on bone scan or imaging examination. Prostate Cancer Specific Mortality (PCSM) was defined as the time from RP to death for PCa or disease related complications while Other-Cause Mortality (OCM) as the time from RP to death not depending for PCa. Prostate Cancer-Specific Survival (PCSS) was defined as the time from RP to PCSM while overall survival (OS) was defined as the time from RP to death from any cause.

\section{Statistical analysis}

All statistical analyses were completed using SPSS v. 19 software (SPSS Inc, IBM Corp, Somers, NY, USA). Cox univariate and multivariate regression models were carried out to identify variables for predicting biochemical recurrence $(\mathrm{BCR})$, clinical progression $(\mathrm{CP})$, prostate cancer specific mortality (PCSM) and other-cause mortality (OCM) from preoperative variables including age, PSA levels, clinical T stage, biopsy Gleason score and from postoperative variables including pathological Gleason score, positive margin status, seminal vesicle invasions, and adjuvant treatment conditions. Biochemical progression-free survival (BPFS), clinical progression-free survival (CPFS), prostate cancer-specific survival (PCSS) and overall survival (OS) were determined using the Kaplan-Meier method and curves were tested with the log-rank test. Life-tables of each subgroup were analyzed using the Wilcoxon (Gehan) test. For all statistical comparisons significance was considered as $\mathrm{p}<0.05$.

\section{RESULTS}

Table-1 lists the baseline characteristics of the subjects included in this study. Median of preoperative PSA level was $20 \mathrm{ng} / \mathrm{mL}$ (range 1-82), median of age of patients was 68 (range 48-78) and CCI was respectively $<2$ and $\geq 2$ in 159 (65.2\%) and 85 (34.8\%) subjects. Upstaging and upgrading was found in $72(29.1 \%)$ and $49(20.08 \%)$ patients and median follow-up was 54.17 months (range 5.4-117.16), 13 (5.3\%) subjects had biochemical progression, 21 (8.6\%) had clinical progression, 7
(2.9\%) died due to prostate cancer and 15 (6.1\%) died due to other causes. 136 (55.7\%) patients did not receive any adjuvant treatment while 108 (44.3\%) received respectively adjuvant or salvage $\mathrm{RT}+\mathrm{ADT}$.

Multivariate Cox proportional hazard analysis showed that pre-operative PSA value at diagnosis is a significant predictive factor for BCR (HR: $1.04 ; \mathrm{p}<0.05)$ and that Gleason Score 8-10 (HR: $2.4 ; \mathrm{p}<0.05)$ and PSMs (HR: $2.01(0.75-3.12) ; \mathrm{p}<$ 0.01 ) were significant predictors for clinical progression (Table-2). None of the pre-operative and post-operative variables were predictors of PCSM and OCM. Kaplan-Meier curves showed no significant differences between groups when considering BPFS, CPFS, CSS and OS. (Figure-1). The over-all 5 -years BPFS, CPFS, PCSS and OS were respectively 94\%, 85\%, 95\% and 87\%. Radical prostatectomy alone was associated with BPFS, CPFS, CSS and OS at 5-years of 97\%, 90\%, 95\% and 86\% respectively, while adjuvant radiation + androgen deprivation therapy was associated with a BPFS, CPFS and CSS at 5-yr of 91\%, 83\%, 95\% and 88\% (Table-3).

\section{DISCUSSION}

In the past, RP was not considered an acceptable treatment in patients with high-risk prostate cancer. However, thanks to the improvements in surgical techniques and technologies, RP and adjuvant treatments are now increasingly being used in selected patients.

The exact definition of high risk is a matter of debate. High-risk, clinically localised disease was classically defined by D'Amico et al. as any combination of the following factors: a prostate-specific antigen (PSA) score $>20 \mathrm{ng} / \mathrm{mL}$, a Gleason score of 8-10, or clinical stage T2c or greater (13). More recently, the National Comprehensive Cancer Network and EAU have modified this definition to include any combination of a clinical T3, a PSA score > $20 \mathrm{ng} / \mathrm{mL}$, or a Gleason score of 8-10.

Several authors suggest the use of a combination of PSA, Gleason score, and clinical stage to predict outcomes after radical prostatectomy (RP) in patients with a PSA $\geq 20 \mathrm{ng} / \mathrm{mL}$, assuming that the use of a single criterion may overestimate the risk of recurrence and may not identify the 
Table 1 - Clinical and pathological characteristics of patients.

\begin{tabular}{|c|c|c|c|c|}
\hline & $\begin{array}{c}\text { Overall } \\
(\mathrm{n}=244)\end{array}$ & $\begin{array}{l}\text { Exclusive RP } \\
\quad(n=136)\end{array}$ & $\begin{array}{l}R T+A D T \\
(n=108)\end{array}$ & $p$-value \\
\hline Median (range) age, years & $68(48-78)$ & $68(53-78)$ & $67(48-78)$ & 0.40 \\
\hline Median (range) PSA at baseline, $\mathrm{ng} / \mathrm{mL}$ & $20(1-82)$ & $14(1-69)$ & $21(3-82)$ & 0.03 \\
\hline CCI, n (\%) & & & & 0.11 \\
\hline$<2$ & $159(65.2)$ & $83(61.0)$ & $76(70.4)$ & \\
\hline$\geq 2$ & $85(34.8)$ & $53(39.0)$ & $32(29.6)$ & \\
\hline Clinical stage, n (\%) & & & & 0.27 \\
\hline T1c & $16(6.6)$ & $12(8.8)$ & $4(3.7)$ & \\
\hline $\mathrm{T} 2$ & $206(84.4)$ & $112(82.4)$ & $94(87.0)$ & \\
\hline ТЗа & $22(9.0)$ & $12(8.8)$ & $10(9.3)$ & \\
\hline Biopsy Gleason score, n (\%) & & & & 0.14 \\
\hline$\leq 6$ & $48(19.7)$ & $32(23.5)$ & $16(14.8)$ & \\
\hline 7 & $43(17.6)$ & $20(14.7)$ & $23(21.3)$ & \\
\hline $8-10$ & $153(62.7)$ & $84(61.8)$ & $69(63.9)$ & \\
\hline Pathological Gleason score, $\mathbf{n}(\%)$ & & & & 0.01 \\
\hline$\leq 6$ & $30(12.3)$ & $20(14.7)$ & $10(9.3)$ & \\
\hline 7 & $105(43.0)$ & $66(48.5)$ & $39(36.1)$ & \\
\hline $8-10$ & $109(44.7)$ & $50(36.8)$ & $59(54.6)$ & \\
\hline Pathological stage, n (\%) & & & & $<0.01$ \\
\hline pT2 & $80(32.8)$ & $64(47.1)$ & $16(14.8)$ & \\
\hline рT3a & $104(42.6)$ & $46(33.8)$ & $58(53.7)$ & \\
\hline рT3b-4 & $60(24.6)$ & $26(19.1)$ & $34(31.5)$ & \\
\hline Upgrading, n (\%) & $49(20.08)$ & $25(18.38)$ & $24(22.22)$ & 0.09 \\
\hline Upstaging, n (\%) & $72(29.1)$ & $34(25.0)$ & $37(34.26)$ & 0.10 \\
\hline PSMs, n (\%) & $86(35.2)$ & $60(55.6)$ & $26(19.1)$ & $<0.01$ \\
\hline SVI, n (\%) & $65(26.6)$ & $0(0.0)$ & $28(26.6)$ & $<0.01$ \\
\hline
\end{tabular}

true high-risk patient (14). In fact, men with a high level of PSA and a Gleason grade $\leq 7$ had very low risk for cancer progression. Alternatively, men with multiple high-risk features (i.e., PSA $>20 \mathrm{ng} / \mathrm{mL}$, biopsy Gleason score 8-10, or clinical stage T3 disease) had poor outcomes despite sur- gery (15).

Data from the randomized controlled trial EORTC 22911 demonstrated that conventional postoperative irradiation significantly improves biochemical progression-free survival and local control compared with a wait-and-see policy at 5 
Table 2 - Multivariate cox regression analysis of preoperative and pathological predictors of biochemical recurrence and clinical progression.

\begin{tabular}{|c|c|c|c|c|}
\hline & \multicolumn{2}{|c|}{ Biochemical Recurrence } & \multicolumn{2}{|c|}{ Clinical Progression } \\
\hline & \multicolumn{2}{|c|}{ Multivariate } & \multicolumn{2}{|c|}{ Multivariate } \\
\hline & $\mathrm{HR}(95 \% \mathrm{Cl})$ & P-value & $\mathrm{HR}(95 \% \mathrm{Cl})$ & P-value \\
\hline Patient age, years & $1.03(0.89-1-19)$ & 0.68 & $1.10(0.94-1.28)$ & 0.23 \\
\hline PSA level, ng/mL & $1.04(1.00-1.06)$ & 0.04 & $0.68(0.98-1.05)$ & 0.68 \\
\hline \multicolumn{5}{|l|}{ Clinical T stage } \\
\hline $\mathrm{T} 1 \mathrm{c}$ & 1.00 (Ref.) & & 1.00 (Ref.) & \\
\hline $\mathrm{T} 2$ & $2.78(0.10-4.63)$ & 0.97 & $1.42(0.1-6.69)$ & 0.96 \\
\hline T3-4 & $4.00(0.10-6.68)$ & 0.96 & $2.97(0.2-6.31)$ & 0.97 \\
\hline \multicolumn{5}{|c|}{ Biopsy Gleason Score } \\
\hline$\leq 6$ & 1.00 (Ref.) & & 1.00 (Ref.) & \\
\hline 7 & $3.07(0.1-3.27)$ & 0.95 & $3.14(0.18-77.76)$ & 0.48 \\
\hline $8-10$ & $6.57(0.2-6.94)$ & 0.95 & $4.25(1.10-5.77)$ & 0.38 \\
\hline \multicolumn{5}{|c|}{ Pathological Gleason Score } \\
\hline$\leq 6$ & 1.00 (Ref.) & & 1.00 (Ref.) & \\
\hline 7 & $1.48(0.50-4.80)$ & 0.53 & $1.2(1.1-1.4)$ & 0.04 \\
\hline $8-10$ & $2.57(0.48-4.22)$ & 0.58 & $2.4(1.0-2.8)$ & 0.03 \\
\hline \multicolumn{5}{|l|}{ Pathological Stage } \\
\hline T2 & 1.00 (Ref.) & & 1.00 (Ref.) & \\
\hline ТЗа & $1.44(1.12-2.56)$ & 0.55 & $2.36(1.74-3.56)$ & 0.50 \\
\hline T3b-T4 & $2.23(0.32-15.54)$ & 0.41 & $3.23(2.02-4.50)$ & 0.30 \\
\hline PSMs, yes vs. no & $1.46(0.84-1.98)$ & 0.72 & $2.01(0.75-3.12)$ & $<0.01$ \\
\hline SVI, no vs. yes & $0.87(0.2-2.66)$ & 0.74 & $0.83(0.04-2.65)$ & 0.64 \\
\hline
\end{tabular}

and 10 years follow-up $(16,17)$.

In addition, results from the SWOG 8794 showed that adjuvant radiotherapy within 18 weeks after radical prostatectomy in a men with pT3NOM0 prostate cancer significantly reduces the risk of PSA recurrence, metastasis and the need for hormonal therapy, and significantly increases survival (18).

More recently, in a retrospective study of Ost et al., it has been showed that adjuvant RT + ADT significantly improved biochemical and clin- ical progression rates after a median follow-up of 5 years in patients with unfavourable pathological findings $(19,20)$.

In our study, good oncological outcomes seem to be obtained even in patients with worse pathological characteristics (i.e. pathological stage $\geq \mathrm{T} 3 \mathrm{No}$ and/or positive surgical margins) who needed adjuvant or salvage treatment like RT + ADT, with an estimated BPFS, CPFS, PCSS and OS of 94\%, 85\%, 95\% and 87\%respectively.

Androgen deprivation given in combi- 
Figure 1 - Kaplan-Meier curve analysis of BFPS, CPFS, PCSS and OS between groups.
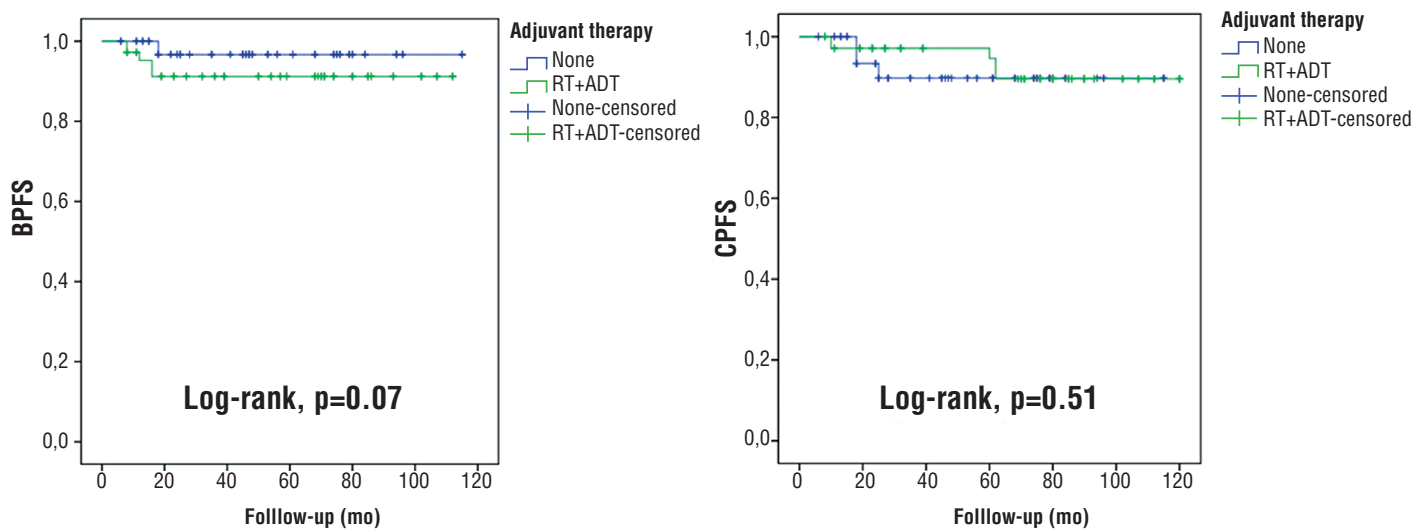

\begin{tabular}{|c|c|c|c|}
\hline No. at risk & $0 \mathrm{mo}$ & $36 \mathrm{mo}$ & $60 \mathrm{mo}$ \\
\hline None & 132 & 76 & 26 \\
\hline RT+ADT & 104 & 71 & 26 \\
\hline
\end{tabular}

\begin{tabular}{|c|c|c|c|}
\hline No. at risk & $0 \mathrm{mo}$ & $36 \mathrm{mo}$ & $60 \mathrm{mo}$ \\
\hline None & 136 & 76 & 26 \\
\hline $\mathrm{RT}+\mathrm{ADT}$ & 108 & 79 & 41 \\
\hline
\end{tabular}
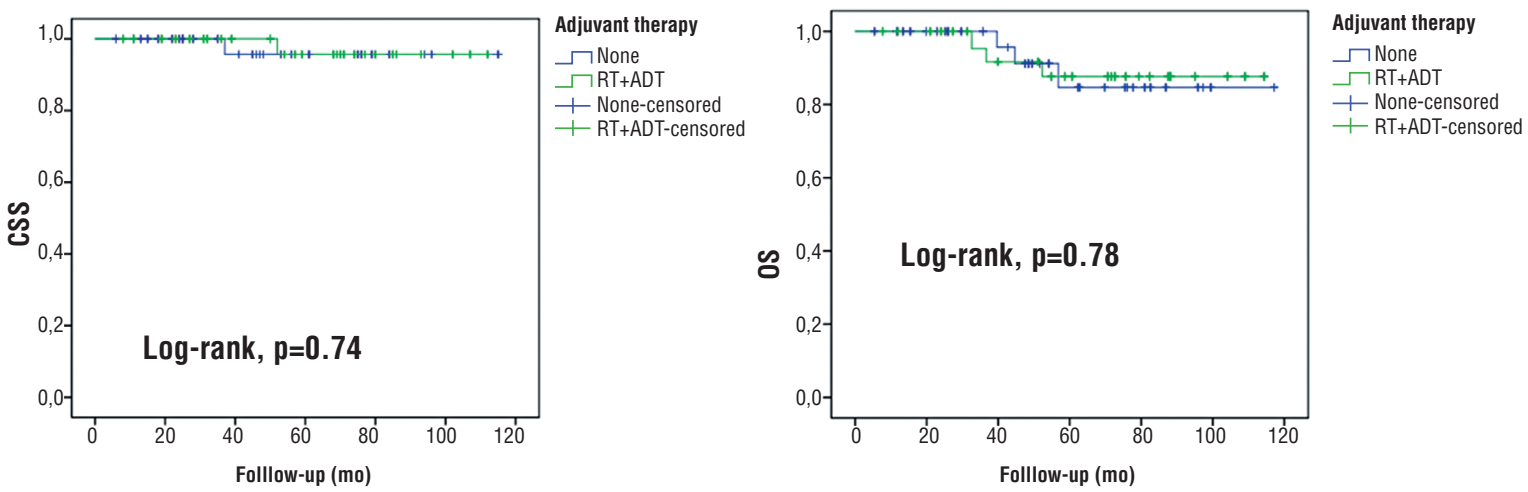

\begin{tabular}{|c|c|c|c|}
\hline No. at risk & $0 \mathrm{mo}$ & $36 \mathrm{mo}$ & $60 \mathrm{mo}$ \\
\hline None & 136 & 80 & 26 \\
\hline RT $+\mathrm{ADT}$ & 108 & 76 & 27 \\
\hline
\end{tabular}

\begin{tabular}{|c|c|c|c|}
\hline No. at risk & $0 \mathrm{mo}$ & $36 \mathrm{mo}$ & $60 \mathrm{mo}$ \\
\hline None & 136 & 89 & 26 \\
\hline RT+ADT & 108 & 78 & 29 \\
\hline
\end{tabular}

Table 3 - Life tables comparison of BPFS, CPFS, PCSS and OS between both groups.

\begin{tabular}{|c|c|c|c|c|c|c|c|c|}
\hline & \multicolumn{2}{|c|}{ BPFS at 5-years } & \multicolumn{2}{|c|}{ CPFS at 5-years } & \multicolumn{2}{|c|}{ PCSS at 5-years } & \multicolumn{2}{|c|}{ OS at 5-years } \\
\hline & $\begin{array}{l}\text { Cumulative } \\
\text { Survival Rate }\end{array}$ & P-value & $\begin{array}{l}\text { Cumulative } \\
\text { Survival Rate }\end{array}$ & P-value & $\begin{array}{l}\text { Cumulative } \\
\text { Survival Rate }\end{array}$ & P-value & $\begin{array}{l}\text { Cumulative } \\
\text { Survival Rate }\end{array}$ & $\mathrm{P}$-value \\
\hline Adjuvant & & 0.20 & & 0.64 & & 0.83 & & 0.90 \\
\hline Exclusive RP & $97 \%$ & & $90 \%$ & & $94 \%$ & & $86 \%$ & \\
\hline RT+ADT & $90 \%$ & & $80 \%$ & & $94 \%$ & & $87 \%$ & \\
\hline
\end{tabular}


nation with RT in men with high risk prostate cancer demonstrates clinical benefits. The advantages appear to be related both to the ability of androgen deprivation to make prostate cancer more susceptible to radiation induced death and by killing or suppressing cancer cells that might have escaped from the prostate gland.

The role of lymph node dissection was addressed by Engel et al., who compared outcomes in LN positive patients with or without RP. They showed a survival benefit for local treatment even in positive lymph node disease, suggesting that RP may result in improved outcomes. However, these results must be viewed with caution given the greater proportion of prostatectomy abandonment in patients with unresectable and therefore more advanced disease (21). In our series, extended lymph node dissection was considered as integral part of the treatment.

Despite the different pathological characteristics of these patients, these tailored multimodality approach could offer benefits, with substantial survival gains of the RT+ADT group. In fact, we did not observe statistically differences in term of BPFS, CPFS, CSS and OS between groups. Certainly, the adjuvant or salvage therapy uniforms the survival rate to those patients who underwent exclusive RP.

However, the crucial question whether the optimum initial strategy should include radiation combined with androgen deprivation therapy at the time of RP, or surgery followed by selective radiation on the basis of pathological findings is still open (22).

Finally, to the best of our knowledge, this is the first study that report similar benefits in term of OS in high-risk prostate cancer patients who underwent a tailored treatment based on pathological features including RP alone and adjuvant or salvage therapy including RT+ADT when clinically required. However, our study contains potential limitations that need to be considered.

One possible limitation is the identification of high-risk prostate cancer patients based on D'Amico definition despite possible favorable features at pathological specimens after surgery.

Moreover, the short follow-up might have underestimated the overall risk of relapse and mortality, because it is well known that PCa progresses slowly and our median follow-up could be considered insufficient (23). Finally, recent observations demonstrated the importance of comorbidities, evaluated as Charlson Comorbidity Index (CCI), when showing long-term survival in highrisk prostate cancer patients (24). In this context, the role of radical prostatectomy even in patients with high risk prostate cancer should be cautious, due to the limited life expectancy. However, the small sample size and the impact of comorbidity on patient survival might have been underestimated in our analyses.

\section{CONCLUSIONS}

Although the heterogeneous pathological characteristics of our cohort of high-risk prostate cancer multimodality, tailored treatment based on $\mathrm{RP}$ and adjuvant or salvage therapy with RT+ADT achieved similar results in terms of BPFS, CPFS, CSS and OS after 5-years of follow-up.

\section{CONFLICT OF INTEREST}

\author{
None declared.
}

\section{REFERENCES}

1. Heidenreich A, Bellmunt J, Bolla M, Joniau S, Mason M, Matveev $\mathrm{V}$, et al.: EAU guidelines on prostate cancer. Part 1: screening, diagnosis, and treatment of clinically localised disease. Eur Urol. 2011; 59: 61-71.

2. Cooperberg MR, Broering JM, Carroll PR: Time trends and local variation in primary treatment of localized prostate câncer. J Clin Oncol. 2010; 28: 1117-23.

3. Morgia G, Russo GI, Berretta M, Privitera S, Kirkali Z: Genitourological cancers in elderly patients. Anticancer Agents Med Chem. 2013; 13: 1391- 405.

4. Russo GI, Cimino S, Castelli T, Favilla V, Urzì D, Veroux M, et al.: Percentage of cancer involvement in positive cores can predict unfavorable disease in men with low-risk prostate cancer but eligible for the prostate cancer international: active surveillance criteria. Urol Oncol. 2014; 32: 291-6.

5. Nguyen PL, Chen MH, Catalona WJ, Moul JW, Sun L, 
D'Amico AV: Predicting prostate cancer mortality among men with intermediate to high-risk disease and multiple unfavorable risk factors. Int J Radiat Oncol Biol Phys. 2009; 73: 659-64.

6. Pilepich MV, Winter K, Lawton CA, Krisch RE, Wolkov HB, Movsas B, et al.: Androgen suppression adjuvant to definitive radiotherapy in prostate carcinoma--long-term results of phase III RTOG 85-31. Int J Radiat Oncol Biol Phys. 2005; 61: 1285-90.

7. Roach M 3rd, Bae K, Speight J, Wolkov HB, Rubin P, Lee $R J$, et al.: Short-term neoadjuvant androgen deprivation therapy and external-beam radiotherapy for locally advanced prostate cancer: long-term results of RTOG 8610. J Clin Oncol. 2008; 26: 585-91.

8. Widmark A, Klepp 0, Solberg A, Damber JE, Angelsen A, Fransson $\mathrm{P}$, et al.: Endocrine treatment, with or without radiotherapy, in locally advanced prostate cancer (SPCG-7/ SFU0-3): an open randomised phase III trial. Lancet. 2009; 373: 301-8. Erratum in: Lancet. 2009; 373: 1174.

9. Ward JF, Slezak JM, Blute ML, Bergstralh EJ, Zincke H: Radical prostatectomy for clinically advanced (cT3) prostate cancer since the advent of prostate-specific antigen testing: 15-year outcome. BJU Int. 2005; 95: 751-6.

10. Berglund RK, Jones JS, Ulchaker JC, Fergany A, Gill I, Kaouk J, et al.: Radical prostatectomy as primary treatment modality for locally advanced prostate cancer: a prospective analysis. Urology. 2006; 67: 1253-6.

11. Carver BS, Bianco FJ Jr, Scardino PT, Eastham JA: Longterm outcome following radical prostatectomy in men with clinical stage T3 prostate cancer. J Urol. 2006; 176: 564-8.

12. Freedland SJ, Partin AW, Humphreys EB, Mangold LA, Walsh PC: Radical prostatectomy for clinical stage T3a disease. Cancer. 2007; 109: 1273-8.

13. D'Amico AV, Whittington R, Malkowicz SB, Schultz D, Blank K, Broderick GA, et al.: Biochemical outcome after radical prostatectomy, external beam radiation therapy, or interstitial radiation therapy for clinically localized prostate cancer. JAMA. 1998; 280: 969-74.

14. Spahn M, Joniau S, Gontero P, Fieuws S, Marchioro G, Tombal B, et al.: Outcome predictors of radical prostatectomy in patients with prostate-specific antigen greater than $20 \mathrm{ng} /$ $\mathrm{ml}$ : a European multi-institutional study of 712 patients. Eur Urol. 2010; 58: 1-7; discussion 10-1.

15. Ploussard G, Masson-Lecomte A, Beauval JB, Ouzzane A, Bonniol $R$, Buge F, et al.: Radical prostatectomy for high-risk prostate cancer defined by preoperative criteria: oncologic follow-up in national multicenter study in 813 patients and assessment of easy-to-use prognostic substratification. Urology. 2011; 78: 607-13.

16. Bolla M, van Poppel H, Collette L, van Cangh P, Vekemans K,
Da Pozzo L, et al.: Postoperative radiotherapy after radical prostatectomy: a randomised controlled trial (EORTC trial 22911). Lancet. 2005; 366: 572-8.

17. Bolla M, van Poppel H, Tombal B, Vekemans K, Da Pozzo L, de Reijke TM, et al.: Postoperative radiotherapy after radical prostatectomy for high-risk prostate cancer: long-term results of a randomised controlled trial (EORTC trial 22911). Lancet. 2012; 380: 2018-27.

18. Thompson IM, Tangen CM, Paradelo J, Lucia MS, Miller G, Troyer D, et al:: Adjuvant radiotherapy for pathological T3NOMO prostate cancer significantly reduces risk of metastases and improves survival: long-term followup of a randomized clinical trial. J Urol. 2009; 181: 956-62.

19. Ost P, Cozzarini C, De Meerleer G, Fiorino C, De Potter B, Briganti $A$, et al.: High-dose adjuvant radiotherapy after radical prostatectomy with or without androgen deprivation therapy. Int J Radiat Oncol Biol Phys. 2012; 83: 960-5.

20. Ost P, Lumen N, Goessaert AS, Fonteyne V, De Troyer B, Jacobs $F$, et al.: High-dose salvage intensity-modulated radiotherapy with or without androgen deprivation after radical prostatectomy for rising or persisting prostatespecific antigen: 5-year results. Eur Urol. 2011; 60: 842-9.

21. Engel J, Bastian PJ, Baur H, Beer V, Chaussy C, Gschwend $\mathrm{JE}$, et al.: Survival benefit of radical prostatectomy in lymph node-positive patients with prostate cancer. Eur Urol. 2010; 57: 754-61.

22. Cooperberg MR: High-risk prostate cancer: treat the prostate. Lancet. 2011; 378: 2056-7.

23. Amling CL, Blute ML, Bergstralh EJ, Seay TM, Slezak J, Zincke H: Long-term hazard of progression after radical prostatectomy for clinically localized prostate cancer: continued risk of biochemical failure after 5 years. $J$ Urol. 2000; 164: 101-5.

24. Briganti A, Spahn M, Joniau S, Gontero P, Bianchi M, Kneitz $B$, et al.: Impact of age and comorbidities on long-term survival of patients with high-risk prostate cancer treated with radical prostatectomy: a multi-institutional competingrisks analysis. Eur Urol. 2013; 63: 693-701.

Correspondence address: Giorgio Ivan Russo, MD

Department of Urology, University of Catania Professor and Chairman Department of Urology: Prof. Giuseppe Morgia School of Medicine Policlinico Hospital University of Catania, Italy Fax: + 3995 378-2373

E-mail: giorgioivan@virgilio.it 